\title{
Increasing stability and toxicity of Pseudomonas exotoxin by attaching an antiproteasic peptide*
}

\author{
Jocelyn Méré, Christophe Chopard, Anne Bonhoure ${ }^{\#}$, Juliette Morlon-Guyot ${ }^{\#}$ and \\ Bruno Beaumelle
}

CPBS, UMR 5236 CNRS, 1919 route de Mende, 34293 MONTPELLIER, France

Published in Biochemistry. 2011 Nov 22;50(46):10052-60

Contact bruno.beaumelle@irim.cnrs.fr

\begin{abstract}
Abbreviations used are: BPTI, bovine pancreatic trypsin inhibitor; DHFR, dihydrofolate reductase; DT, diphtheria, toxin; DTA, DT A-chain; DTB, DT B-chain; PE, Pseudomonas exotoxin A; RTA, ricin A-chain; rRTA, recombinant RTA; RTB, ricin B-chain.
\end{abstract}

\begin{abstract}
Trypsin-like activities are present within the endocytic pathway and allow cells to inactivate a fraction of incoming toxins, such as Pseudomonas exotoxin (PE), that require endocytic uptake before reaching the cytosol to inactivate protein synthesis. PE is a favorite toxin for building immunotoxins. The latter are promising molecules to fight cancer or transplant rejection, and producing more active toxins is a key challenge. More broadly, increasing protein stability is a potentially useful approach to improve the efficiency of therapeutic proteins. We report here that fusing an antiproteasic peptide (bovine pancreatic trypsin inhibitor, BPTI) to PE increases its toxicity to human cancer cell lines by 20-40 fold. Confocal microscopic examination of toxin endocytosis, digestion and immunoprecipitation experiments showed that the fused antiproteasic peptide specifically protects PE from trypsinlike activities. Hence, the attached BPTI acts as a bodyguard for the toxin within the endocytic pathway. Moreover, it increased the PE elimination half-time in mice by $70 \%$, indicating that the fused BPTI stabilizes the toxin in vivo. This BPTI-fusion approach may be useful for protecting other circulating or internalized proteins of therapeutic interest from premature degradation.
\end{abstract}

\footnotetext{
* This study was supported by the Association de la Recherche sur le Cancer.
} 
Immunotoxins are promising agents for treating cancer and transplant rejection (1-3). These hybrid molecules are usually prepared by linking a monoclonal antibody (sometimes restricted to its antigen binding portion) to a toxin devoid of its receptor-binding domain (2). Most immunotoxins are prepared using toxins targeting the protein synthesis system, such as diphtheria toxin (DT), Pseudomonas exotoxin (PE) or ricin (2). Production of more potent versions of these toxins to obtain more efficient immunotoxins would undoubtedly facilitate the clinical use of these therapeutic agents.

Ricin is an heterodimeric protein. The A-chain is an enzyme that is able to inactivate protein synthesis, resulting in cell death. The B-chain is a lectin that is responsible for cell binding (4). The bacterial toxins DT and PE are made of three structural and functional domains. They enable the toxin to bind to its receptor, translocate to the cytosol and inactivate protein synthesis, respectively (5) (see Fig.1 for details). The catalytic activity of PE and DT catalyses the ADP-ribosylation of elongation factor 2 (EF2), thereby blocking protein synthesis.

Cells can process internalized proteins before they reach lysosomes. A number of proteolytic activities, including trypsin- and furin-like activities, have indeed been associated with various elements of the endocytic pathway, and toxins are attractive tools for studying this processing. While ricin, perhaps due to its packed structure (6) is intrinsically resistant to most animal-cell proteases (7), toxicity of DT and PE is tightly associated with endosomal proteolysis (8). Cell-associated trypsin or furin can cleave DT within the Arg-rich interchain loop (Fig.1). This processing results in toxin activation that is required for cytotoxicity (9) and activated, nicked DT is resistant to further trypsin digestion (up to $1 \mu \mathrm{g} / \mathrm{ml}(10)$ ).

Upon endocytosis, PE can be similarly activated by trypsin- and furin-like activities that cut the toxin after $\operatorname{Arg} 279$, within a disulfide stabilized loop at the beginning of the translocation domain (Fig.1). Cleavage at this site, then disulfide reduction, generates a 37 $\mathrm{kDa}$ carboxyl-terminal active fragment that translocates to the cytosol following retrograde transport to the ER and is involved in the intoxication process $(11,12)$. Entire PE can also cross the endosome membrane to reach the cytosol $(12,13)$. Nevertheless, PE processing by trypsin-like activities during endocytosis can result in toxin inactivation due, for instance, to a cleavage after Arg490, i.e. within its catalytic domain (11). An attempt was first made to protect PE from cell trypsin-like activity by inhibiting this processing after Arg490, using point mutations within this area of the molecule. Surprisingly, mutant PE that are resistant to cleavage after Arg490 by purified trypsin showed improved stability in mouse blood, but not enhanced toxicity as compared to PE (14). Similar data were obtained when PE was 
conjugated to polyethylene glycol. This modification prolonged the PE elimination half-life in mice, while cytotoxicity remained unaffected (15).

Once delivered to the cytosol, incoming toxins will meet the proteasome that can also neutralize toxins. The identity of the first residue is a major determinant for recognition by this degradation system (16). This N-end rule also applies for toxins, and mutating the first residue of the DT A-chain revealed a linear relationship between intracellular stability and toxicity. Nevertheless, none of these mutants were more toxic than native DT (17).

Because neither point mutations $(14,17)$, nor conjugation to polyethylene glycol (15) succeeded to produce more active toxins, it therefore remained to be determined whether improving toxin stability would enable generation of more potent molecules. In this study, we showed that fusing bovine pancreatic trypsin inhibitor (BPTI) to PE enhances its cytotoxicity, intracellular stability as well as its elimination half-life in mice. This approach could be applied to stabilize other clinically valuable circulating proteins such as hormones and growth factors that are susceptible to trypsin $(18,19)$.

\section{Experimental Procedures}

\section{Reagents}

Most chemicals were obtained from Sigma, cells from the American Tissue Culture Collection and pure RTB from Inland Laboratories (Austin, Texas). Purified furin and 6biotin-17-NAD were from R\&D systems. Goat and rabbit anti-PE antibodies were from List Biological Laboratories and Sigma, respectively, and were affinity purified before use (20). The DT used in this study is an attenuated version (DT-E148S) (21) suitable for expression in E. coli.

\section{DNA manipulations}

A conventional PCR-based approach was used to prepare all constructions (7), in pET-3d, using appropriate restriction sites. Target plasmids carrying DT-E148S (21), RTA (7), PE (22) and BPTI (23) have been described. Chimeras in which BPTI was linked to the Nterminus of toxin $\mathrm{X}$ consisted of the OmpA signal sequence followed by the five residues from mature OmpA (Ala-Pro-Lys-Asp-Asn; to enable cleavage by the signal peptidase), ProGln, BPTI, a spacer peptide (Ala-Ser-Ala-Ser-Thr-Pro-Glu-Pro-Asp-Pro-Glu-Lys-Leu (7)) and X. BPTI and DTB were connected by the same spacer when BPTI was attached to the DTB carboxyl terminal (see Fig.1 for construction details). All PCR-amplified DNA was 
sequenced to check for the absence of mutations. The complete sequence of BPTI-PE is provided as supplemental Fig.1.

\section{Expression and purification of fusion proteins}

Chimeras were expressed in ( $\lambda \mathrm{DE} 3)$ BL21-transfected E. coli, and purified from the periplasm using ion exchange chromatography. A CM-sepharose column was used for RTA (24), and a Q-Sepharose column for bacterial toxin (DT and PE (22)) purification. Western blots using anti-toxin and anti-BPTI antibodies were used to confirm the identity of the chimeras. PE, BPTI-RTA and recombinant RTA (rRTA) were $>95 \%$ pure after this single chromatographic step, while DT, BPTI-DT, DT-BPTI and BPTI-PE were further purified on a mono-P column, to reach $>95 \%$ homogeneity. To associate rRTA or BPTI-RTA to RTB, equimolecular amounts of $\mathrm{A}$ - and B-chains $(30 \mu \mathrm{M})$ were treated with $8 \mathrm{mM}$ reduced glutathione for $3 \mathrm{~h}$ at room temperature before overnight dialysis at $4^{\circ} \mathrm{C}(7)$.

\section{In vitro cleavage of PE and BPTI-PE by proteases}

Toxins $(5 \mu \mathrm{g})$ were incubated at $37^{\circ} \mathrm{C}$ for $30 \mathrm{~min}$ with trypsin concentrations ranging from 0.3 to $30 \mu \mathrm{g} / \mathrm{ml}$, in $110 \mathrm{mM} \mathrm{NaCl}, 20 \mathrm{mM}$ Tris-HCl, pH 7.5, or in $110 \mathrm{mM} \mathrm{NaCl}, 20 \mathrm{mM}$ sodium acetate, $\mathrm{pH} 5.5$, in a final volume of $20 \mu \mathrm{l}$. To study furin processing, toxins $(6 \mu \mathrm{g})$ were incubated at $25^{\circ} \mathrm{C}$ for 4 to $16 \mathrm{~h}$ with $0-25 \mathrm{U}$ furin in $15 \mu \mathrm{l}$ of $1 \mathrm{mM} \mathrm{CaCl}_{2}, 100 \mathrm{mM}$ sodium acetate, $\mathrm{pH}$ 5.5. Digestions were terminated by boiling for $3 \mathrm{~min}$ in reducing sample buffer before SDS/PAGE and Coomassie blue or Sypro ruby staining. Furin activity was assessed by monitoring the production of the $37 \mathrm{kDa}$-terminal and the $28 \mathrm{kDa} \mathrm{N}$-terminal fragments from PE (25). Furin processing of BPTI-PE generates a larger N-terminal fragment $(\sim 34 \mathrm{kDa})$, due to the presence of BPTI. The bands corresponding to the entire toxin and processed fragments were quantified using imageQuant (GE Healthcare).

\section{Assay for PE catalytic activity}

The ADP ribosylation activity of PE was tested as described (26) using partially purified EF2 (27). Toxins were first activated using $4 \mathrm{M}$ urea and $40 \mathrm{mM}$ dithiothreitol (14). Each assay contained $6 \mu$ l of buffer (100 mM dithiothreitol, 0.5 mM EDTA, $100 \mathrm{mM}$ Tris-HCl, pH 8), 3 $\mu 1$ of purified EF2, $3 \mu \mathrm{l}$ of biotin-labeled NAD (150 $\mu \mathrm{M})$, and $3 \mu 1$ of toxin (0-5 pmoles). Control tubes contained everything but enzyme. Incubation was performed at $25^{\circ} \mathrm{C}$ for 30 min and was stopped by adding reducing sample buffer and boiling. After SDS/PAGE, the gel was blotted onto nitrocellulose, blocked in 3\% BSA and biotin was detected using 
extravidin-peroxidase and $\mathrm{ECL}^{+}$(GE Healthcare). Films were exposed within their linear range of detection, scanned and EF2 bands were quantified using ImageQuant. No other bands were present.

\section{Assay for BPTI anti-trypsin activity}

This FRET assay was performed as described before (28), with minor modifications. Briefly, 0-40 pmole of PE, BPTI-PE or BPTI were incubated with 20 pmoles of trypsin and $2 \mu \mathrm{g}$ of casein-fluorescein in $0.2 \mathrm{ml}$ of TBS $(150 \mathrm{mM} \mathrm{NaCl}, 20 \mathrm{mM}$ Tris, $\mathrm{pH}$ 8.0) in a white 96-well plate. Fluorescence was monitored every $30 \mathrm{~min}$ for $90 \mathrm{~min}$ using a polarstar omega multiplate reader equipped with 485/520 nm excitation/emission filters. Controls did not contain trypsin. Under these conditions, casein-fluorescein digestion by trypsin for $1 \mathrm{~h}$ resulted in a 3-fold increase in fluorescence.

\section{Assay for BPTI trypsin-binding activity}

Trypsin-agarose ( $5 \mu 1$ of gel $~ 215$ pmoles trypsin) was washed twice in TBS and incubated for $15 \mathrm{~min}$ at $25^{\circ} \mathrm{C}$ with 75,150 or 260 pmoles of PE, BPTI-PE or BPTI in $20 \mu 1$ of TBS. After washing three times with TBS containing 0.1\% Tween-20, gel-bound proteins were eluted by boiling in reducing sample buffer before SDS/PAGE. Gels were stained with Sypro ruby, imaged and bands were quantified using ImageQuant.

\section{Immunoprecipitation}

PE (5 nM) was added to $1.5 \times 10^{7}$ subconfluent L929 cells. After $4 \mathrm{~h}$ at $37^{\circ} \mathrm{C}$, cells were washed with PBS and a chase of 30 min was performed to allow internalisation of plasma membrane-bound toxin. Cells were then lysed in $1 \mathrm{ml}$ of RIPA buffer (22). After $5 \mathrm{~min}$ on ice, insoluble material was removed by centrifugation at $4^{\circ} \mathrm{C}$. The cleared lysate received 6 $\mu \mathrm{g}$ of goat anti-PE antibodies, was mixed for $1 \mathrm{~h}$ on a rotating wheel before adding $20 \mu \mathrm{l}$ of protein G-sepharose. After $1 \mathrm{~h}$ on the wheel, immune complexes were recovered by centrifugation, washed, eluted by boiling in sample buffer and separated by SDS/PAGE. The gel was transferred to nitrocellulose for visualization using anti-PE antibodies then peroxidase-conjugated protein $\mathrm{G}$ and $\mathrm{ECL}^{+}$. Bands from five different experiments were quantified using ImageQuant.

\section{Confocal microscopy}


L929 cells grown on coverslips were labeled for 45 min at $37^{\circ} \mathrm{C}$ with $100 \mathrm{nM}$ transferrinfluorescein and $15 \mathrm{nM}$ of PE or BPTI-PE in DMEM supplemented with $0.2 \mathrm{mg} / \mathrm{ml} \mathrm{BSA}$. Cells were washed, fixed in $3.7 \%$ paraformaldehyde that was then quenched using $50 \mathrm{mM}$ ammonium chloride. After permeabilization in PBS containing $0.05 \%$ saponin and $1 \mathrm{mg} / \mathrm{ml}$ BSA, cells were labeled with goat anti-PE antibodies that were revealed using rhodaminelabeled donkey anti-goat IgG. Cells were finally mounted for examination under a Leica confocal microscope (12). The ImageQuant software (GE Healthcare) was used to analyze cell images $(30<\mathrm{n}<40)$ in order to quantify signals from endocytosed material. Internalized transferrin-fluorescein signal was used to normalize PE data (see Results).

\section{Toxicity measurements}

Cells (5000 Jurkat, 6000 L929, 8000 K562, 10000 A431, 30000 MCF7 or HepG2) in RPMI $/ 10 \%$ FCS were seeded in 96-well plates. Toxin solutions (and monensin or antibody as indicated) were added after $2 \mathrm{~h}$ at $37^{\circ} \mathrm{C}$. One day after, ${ }^{35} \mathrm{~S}$-methionine/cysteine (trans-label, $0.25 \mu \mathrm{Ci}$ ) was added for $24 \mathrm{~h}$. Medium was then gently removed (after plate centrifugation for non-adherent cells) and cells were solubilized in $0.1 \mathrm{~N} \mathrm{NaOH}$ before protein precipitation with TCA. Proteins were collected onto fiberglass filters, and washed before radioactivity determination. Background incorporation was obtained from cells treated with $1 \mathrm{mM}$ cycloheximide (7).

\section{Pharmacokinetics}

Female Swiss OF1 mice (25-30 g, Iffa-Credo) were injected with PE or BPTI-PE ( $2 \mu \mathrm{g}$ in 200 $\mu 1 \mathrm{PBS} / 0.2 \% \mathrm{BSA})$ into the tail vein. Blood samples $(30 \mu \mathrm{l})$ were collected 2 to $120 \mathrm{~min}$ after injection. Each mouse was bled no more than five times. Samples were allowed to clot on ice, then centrifuged to obtain the serum. Toxin concentrations were assayed by ELISA. To this end, 96-well plates were coated with goat anti-PE antibodies $(1 \mu \mathrm{g} / \mathrm{ml})$, then blocked with PBS/milk (8\% w/v) for two hours. Sera and standards diluted in PBS/BSA (3\%) were added before successive $1 \mathrm{~h}$ incubations with rabbit anti-PE antibodies (1:2000) and peroxidaseconjugated goat anti-rabbit antibodies in PBS/milk. After each incubation step, plates were washed with PBS/Tween (0.05\%). Finally, a solution of 3,3',5'5-tetramethylbenzidine (Sigma) was added. After $15 \mathrm{~min}$, the reaction was stopped with $0.5 \mathrm{M}$ sulfuric acid, absorbance at $450 \mathrm{~nm}$ was read and the data were analyzed using the Pk-fit software package (29). 


\section{Results}

A large fraction of internalized PE is inactivated by trypsin-like activity in L929 cells (14). We reasoned that it should be possible to increase PE stability within the endocytic pathway by providing it with an antiproteasic moiety that would act as a bodyguard. A specific trypsin inhibitor was needed, since PE processing by furin is important for cytotoxicity (11). BPTI (aprotinin, a small $6.5 \mathrm{kDa}$ polypeptide (23)) was a good candidate to fulfill this function since it inhibits trypsin but not furin (30). As control toxins, we used ricin and DT, which are not inactivated by proteolysis during initial uptake by most cell lines, and are only degraded when they reach lysosomes $(31,32)$.

Fig.1 shows the chimeras used in this study. BPTI was fused to RTA, DTA, DTB, or PE via a linker peptide (7). BPTI has three disulfide bonds that stabilize the molecule (23). Fusion proteins were therefore expressed and purified from E.coli periplasm to enable disulfide bridge formation.

\section{Fused BPTI impairs DTA and RTA translocation}

Fusing BPTI to DTB, which does not bear the toxic catalytic activity and is not transported to the cytosol (33), generated DT-BPTI that was as toxic as DT (Fig.2A). Nevertheless, things were different when BPTI was fused to DTA-chain since the resulting BPTI-DT was virtually not toxic (Fig.2A). This result is in agreement with data obtained using a dihydrofolate reductase (DHFR) -DT conjugate (34), which indicated that DHFR has to unfold during DHFR-DTA translocation to the cytosol. BPTI is a tightly folded protein that is difficult to transfer through membranes (35). Hence, the fused BPTI likely hampered DTA translocation to the cytosol.

Similar data were obtained using ricin. BPTI-RTA was associated with RTB to prepare BPTI-ricin. The latter was found to be as stable as control ricin within cells according to the results of both confocal microscopic examination and immunoprecipitation using antiRTA antibodies (data not shown). Nevertheless, BPTI-ricin was 50-fold less toxic to L929 than control ricin (Fig.2A). Just as for DT, these data confirm a previous study using DHFR, and showing that RTA passenger protein has to unfold for translocation to the cytosol (7).

Altogether these data indicate that the fused BPTI did not interfere with cytotoxicity as long as the carrier toxin chain does not have to cross membranes. Conversely, fusing BPTI to A-chains inhibits toxicity, likely because BPTI unfolding for membrane translocation is difficult (35). 


\section{BPTI fusion enhances PE toxicity}

The most striking result from this study was obtained when BPTI was fused to the PE Nterminus: toxicity to L929 mouse fibroblasts was enhanced by 40 -fold, i.e. $\mathrm{IC}_{50}$ below $10^{-13} \mathrm{M}$ were reached (Fig.2A). Since PE is one of the favorite toxins for building immunotoxins (2), we examined whether BPTI-PE was also superior to PE for killing human tumor cell lines. We tested Jurkat (acute T-cell leukemia), K562 (chronic myelogenous leukemia), HepG2 (hepatocellular carcinoma), MCF7 (mammary gland adenocarcinoma) and A431 (epidermoid carcinoma) cell lines. In all cases, BPTI-PE was 20-42 fold more efficient than PE in killing these cells (Fig.2B).

It was important to control whether fusion was actually required for toxicity enhancement. We therefore assessed the effect of a large excess (over a thousand-fold) of soluble BPTI on PE cytotoxicity. No improvement in toxicity can be achieved by adding BPTI to the cell culture medium (Fig.2C). The fused BPTI was therefore directly responsible for the gain in PE toxicity. We then examined whether toxicity enhancement could be related to a toxic effect of the fused BPTI. To this end, we specifically neutralized the PE moiety of the BPTI-PE chimera using anti-PE antibodies or monensin. The latter protect cells from PE by impairing $\mathrm{PE}$ insertion into the endosomal membrane that is required before translocation $(13,20)$. PE and BPTI-PE toxicities were inhibited to the same extent by anti-PE antibodies or monensin (Fig.2C). The PE moiety of the BPTI-PE chimera was therefore entirely responsible for cell-killing activity.

\section{BPTI-PE displays both trypsin-inhibition and PE catalytic activity}

To determine the basis of BPTI-PE cytotoxic activity we first checked whether PE catalytic activity was affected by the fusion. It can be seen in Fig.3 that EF2-ADP-ribosylating activities of PE and BPTI-PE are virtually identical. Hence, BPTI fusion does not enhance PE toxicity by increasing its enzymatic activity. We also examined whether the BPTI portion of the BPTI-PE chimera was functional in trans. To this end we used a conventional FRET protease assay in which the substrate is casein-fluorescein whose fluorescence is quenched by fluorescence homotransfer, and increases upon proteolysis. A comparison of the anti-trypsin activities of BPTI and BPTI-PE in this assay showed that BPTI-PE preserved $\sim 45 \%$ of the BPTI capacity to protect casein against trypsin (Fig.4A). Because BPTI-PE is 10-fold bigger than BPTI, we concluded that BPTI-PE is an effective trypsin inhibitor and that the BPTI portion of the chimera was functional. To confirm this point, we assessed whether BPTI-PE could bind trypsin. It is indeed well established that BPTI has a strong affinity for trypsin $(\mathrm{Kd}$ 
$\sim 6 \times 10^{-14} \mathrm{M}$ ) and that the resulting BPTI-trypsin complex is extremely stable (half-life of $\sim 17$ weeks) (36). Both BPTI and BPTI-PE, but not PE, efficiently bound to trypsin-agarose, confirming that BPTI is functional in BPTI-PE (Fig.4B).

\section{BPTI-PE is correctly processed by furin}

Because PE processing by furin upon uptake is thought to be important for cytotoxicity (37), we examined whether BPTI-PE was processed by furin. PE cleavage by furin generates a characteristic C-terminal $37 \mathrm{kDa}$ fragment, and a N-terminal $28 \mathrm{kDa}$ fragment (25). The size of the latter increases to $\sim 34 \mathrm{kDa}$ upon BPTI fusion. We performed a furin concentration- and time-dependent study of PE and BPTI-PE processing by purified furin. Results showed that these proteins were processed by furin with a similar efficiency (Fig.5). Collectively, these biochemical data indicated that the fusion of BPTI to PE affect neither the catalytic activity nor the furin-mediated processing of the toxin, while BPTI antiproteasic activity was moderately affected by the fusion.

\section{Fused BPTI protects PE from endosomal trypsin-like activities}

We then tested the extent of PE protection from trypsin due to BPTI fusion, i.e. protection in cis. We performed these assays both under neutral or acidic conditions, using $\mathrm{pH} 5.5$ that is an average $\mathrm{pH}$ within early endosomes (38). Strikingly, even for high trypsin concentrations (up to $30 \mu \mathrm{g} / \mathrm{ml}$ ) that entirely digest PE, BPTI-PE remains intact whatever the $\mathrm{pH}$ (Fig. 6). Hence, the fused BPTI fulfilled its role in vitro. We then examined whether this was also the case within cells.

Immunoprecipitation experiments (Fig.7A and 7B) showed that, for the same extracellularly applied toxin concentration, the amounts of intact toxin, furin-generated 37 $\mathrm{kDa}$ fragment and other proteolysis products generated by cells during uptake were greatly enhanced by the BPTI fusion. For cytotoxic fragments, i.e. entire toxin and the $37 \mathrm{kDa}$ fragment, a two- to six-fold increase in the intracellular concentration (5-fold on average) was observed after attaching BPTI. These immunoprecipitation data also showed that fused BPTI prevents PE degradation by cell trypsin-like activities while preserving sensitivity to furin. Such PE processing is thought to take place within the endocytic pathway (8), and we performed immunofluorescence experiments to examine whether endosomal BPTI-PE was significantly protected from degradation as compared to endosomal PE.

PE uptake kinetics was not affected by BPTI fusion (data not shown). As observed earlier for PE $(12,39)$, both PE and BPTI-PE were concentrated upon endocytosis within the 
pericentriolar recycling compartment of L929 cells, which is efficiently labeled with fluorescent transferrin. While the same amount of toxin was applied to cells, the resulting intracellular staining was much more intense when BPTI-PE was used (Fig.8A).

Quantification of confocal images using fluorescent transferrin to normalize PE data showed that a 5-fold stronger signal was obtained when cells were labelled with BPTI-PE compared to when PE was used (Fig.8B). This result confirms immunoprecipitation data and indicates that the BPTI fusion protects PE during endocytic uptake.

\section{The BPTI fusion increases PE elimination half-time in mice}

To finish, it was interesting to examine the effect of the BPTI fusion on PE elimination in vivo. The toxin levels in mice sera after intravenous injection of PE or BPTI-PE were assayed by ELISA. Toxicity assays that enabled quantification of biologically active molecules provided identical results (not shown). Toxin disappearance from the serum was biexponential (Fig.9) indicating that the toxin distributes according to a two-compartment model (40). The data were fitted using a pharmacokinetic data analysis software (29). Results of this analysis are presented in Table 1 . The initial distribution phase was rapid for both toxins ( $\mathrm{t} 1 \frac{1}{2}$ distribution $0.6-0.8 \mathrm{~min}$ ), but the BPTI fusion increased $\sim 3$-fold the PE apparent distribution volume, thereby explaining the rapid initial drop in BPTI-PE concentration during the first $15 \mathrm{~min}$. It can be seen from the second part of the curve (after $15 \mathrm{~min}$ ) that BPTI-PE was more slowly eliminated than PE, with corresponding elimination half-times of $31 \mathrm{~min}$ and $18 \mathrm{~min}$, respectively. These effects on the pharmacokinetics properties of PE directly resulted from BPTI fusion since a control conjugate between bovine RNAse A and PE behaved like PE (data not shown). Hence, BPTI fusion induces interesting modifications of PE pharmacokinetics parameters with a greater distribution volume and a longer elimination half-time. 


\section{Discussion}

The main finding of this study was the strong increase in PE toxicity resulting from BPTI fusion to its N-terminus, i.e. to the PE receptor binding domain. This toxicity enhancement was due to the protection provided to PE by the fused BPTI toward trypsin-like activities present within the endocytic pathway. Nevertheless, when conjugated to an A-chain of a trypsin insensitive toxin such as DT or ricin, the stable folding of BPTI (35) severely hampered (RTA) or even blocked (DTA) toxin A-chain delivery to the cytosol which is required for toxicity. Different conclusions can therefore be drawn from the effect of BPTI fusion to these three toxins. First, RTA appears to be a more efficient vehicle than DTA for bringing folded proteins into the cytosol. Secondly, BPTI fusion seems to selectively increase the toxicity of trypsin vulnerable toxins such as PE.

BPTI fusion to PE resulted in the stabilization of several intracellular fragments, such as the entire protein and the C-terminal $37 \mathrm{kDa}$ fragment (Fig.7). These results were therefore not informative regarding whether PE intoxication requires processing, and especially the production of the $37 \mathrm{kDa}$ fragment (12).

The molecular mechanism underlying the superior antiproteasic properties of the BPTI fusion relative to unconjugated BPTI is unclear. Nevertheless, it seems reasonable to assume that the antitrypsin peptide should be kept as close as possible to the target protein to ensure optimum protection. Hence, the fused BPTI seems to mimic a high local concentration of BPTI and acts as a bodyguard for the toxin. BPTI is 10-fold smaller than PE, and the 59 basic residues (Arg+Lys) of PE, i.e. its potential trypsin processing sites are widespread between domains. It is thus unlikely that BPTI, which is fused to the large domain I of PE, could protect the entire toxin by steric hindrance.

BPTI fusion induced interesting modifications in PE pharmacokinetic parameters in mice, enhancing the apparent distribution volume by 3-fold and the elimination half-life by $72 \%$. The latter benefit probably results from protection provided by the fused BPTI with respect to circulating or cell-associated trypsin-like activities. Hence, BPTI tagging should allow more efficient PE delivery to tissues and a longer half-life in the bloodstream after injection.

PE resistance to trypsin cleavage after Arg490 was already obtained through mutations around this trypsin processing site (14). The weak toxicity of these mutants compared to BPTI-PE can look surprising. This difference in cytotoxicity is likely due to the existence of other trypsin-processing sites within PE in addition to the two reported loops, one containing Arg279 and the other Arg490 (11). Since fragments generated by cleavage within these loops 
are stable enough to be recovered by immunoprecipitation under appropriate conditions (41), they are likely stable, dead-end products of proteolysis. Since PE owns more than $40 \mathrm{Arg}$, other trypsin sites likely exist and, according to the superiority of BPTI-PE over PE-Arg490 mutants, their cleavage likely triggers complete degradation of the molecule.

Several improved PE variants have been produced. It was first found that replacing PE C-terminal sequence with the ER retrieval motif KDEL generated a 2- to 3-fold more active toxin $(42,43)$. More recently, a 7-fold more toxic molecule was obtained when PE translocation domain was mutated to favor insertion into the endosome membrane (13). Nevertheless, with a 20- to 40-fold increase in toxicity BPTI-PE is by far the most efficient PE mutant ever obtained. Moreover, BPTI is weakly immunogenic, and already used in humans during surgery interventions on heart (44) or liver (45). Hence, BPTI-PE could have some therapeutic applications through the generation of more potent imunotoxins (1-3). More generally, the BPTI fusion approach could also be useful for stabilizing, and therefore maintaining the biological activity of circulating proteins of therapeutic interest such as cytokines or hormones.

\section{Acknowledgements}

We thank Chritine Farenc for the pharmacokinetic analysis, Patrice Boquet (Nice) and Daniel Gillet (Paris) for providing us with the DT-E148S construct, as well as Prof. G. Georgiou and Dr. Zhan (Austin) for the BPTI clone and anti-BPTI antibodies.

\section{Supplemental Information Paragraph}

Supplemental materials can be accessed free of charge online at http://pubs.acs.org 


\section{References}

(1) Pastan, I., Hassan, R., Fitzgerald, D. J., and Kreitman, R. J. (2006) Immunotoxin therapy of cancer. Nat Rev Cancer 6, 559-565.

(2) Pastan, I., Hassan, R., FitzGerald, D. J., and Kreitman, R. J. (2007) Immunotoxin treatment of cancer. Annu Rev Med 58, 221-237.

(3) Hetzel, C., Bachran, C., Tur, M. K., Fuchs, H., and Stocker, M. (2009) Improved immunotoxins with novel functional elements. Curr Pharm Des 15, 2700-2711.

(4) Lord, J. M., Roberts, L. M., and Robertus, J. D. (1994) Ricin: structure, mode of action, and some current applications. FASEB $J$ 8, 201-208.

(5) Deng, Q., and Barbieri, J. T. (2008) Molecular mechanisms of the cytotoxicity of ADPribosylating toxins. Annu Rev Microbiol 62, 271-288.

(6) Montfort, W., villafranca, J. E., Monzingo, A. F., Ernst, S. R., Katzin, B., Rutenber, E., Xuong, N. H., Hamlin, R., and Robertus, J. D. (1987) The three-dimensional structure of ricin at 2.8 A. J Biol Chem 262, 5398-5403.

(7) Beaumelle, B., Taupiac, M. P., Lord, J. M., and Roberts, L. M. (1997) Ricin A chain can transport unfolded dihydrofolate reductase into the cytosol. J Biol Chem 272, 22097-22102.

(8) Gordon, V. M., Klimpel, K. R., Arora, N., Henderson, M. A., and Leppla, S. H. (1995) Proteolytic activation of bacterial toxins by eukaryotic cells is performed by furin and by additional cellular proteases. Infect Immun 63, 82-87.

(9) Tsuneoka, M., Nakayama, K., Hatsuzawa, K., Komada, M., Kitamura, N., and Mekada, E. (1993) Evidence for involvement of Furin in cleavage and activation of Diphtheria Toxin. J Biol Chem 268, 26461-26465.

(10) Drazin, R., Kandel, J., and Collier, R. J. (1971) Structure and activity of diphtheria toxin. II. Attack by trypsin at a specific site within the intact toxin molecule. J Biol Chem 246, 1504-1510.

(11) Chiron, M. F., Ogata, M., and FitzGerald, D. (1996) Pseudomonas exotoxin exhibits increased sensitivity to furin when sequences at the cleavage site are mutated to resemble the arginine-rich loop of diphtheria toxin. Mol Microbiol 22, 769-778.

(12) Morlon-Guyot, J., Méré, J., Bonhoure, A., and Beaumelle, B. (2009) Processing of Pseudomonas exotoxin A is dispensable for cell intoxication. Infect Immun 77, 30903099.

(13) Méré, J., Morlon-Guyot, J., Bonhoure, A., Chiche, L., and Beaumelle, B. (2005) Acidtriggered Membrane Insertion of Pseudomonas Exotoxin A Involves an Original Mechanism Based on pH-regulated Tryptophan Exposure. J Biol Chem 280, 2119421201.

(14) Brinkmann, U., Pai, L. H., FitzGerald, D. J., and Pastan, I. (1992) Alteration of a protease-sensitive region of Pseudomonas exotoxin prolongs its survival in the circulation of mice. Proc Natl Acad Sci U S A 89, 3065-3069.

(15) Kuan, C. T., Wang, Q. C., and Pastan, I. (1994) Pseudomonas exotoxin A mutants. Replacement of surface exposed residues in domain II with cysteine residues that can be modified with polyethylene glycol in a site-specific manner. J Biol Chem 269, 76107616.

(16) Varshavsky, A. (1996) The N-end rule: functions, mysteries, uses. Proc Natl Acad Sci U S A 93, 12142-12149.

(17) Falnes, P. O., and Olsnes, S. (1998) Modulation of the intracellular stability and toxicity of diphtheria toxin through degradation by the N-end rule pathway. Embo J 17, 615625. 
(18) Duprez, V., and Dautry-Varsat, A. (1986) Receptor-mediated endocytosis of interleukin 2 in a human tumor T cell line. Degradation of interleukin 2 and evidence for the absence of recycling of interleukin receptors. J Biol Chem 261, 15450-15454.

(19) Renfrew, C. A., and Hubbard, A. L. (1991) Sequential processing of epidermal growth factor in early and late endosomes of rat liver. J Biol Chem 266, 4348-4356.

(20) Alami, M., Taupiac, M. P., Reggio, H., Bienvenue, A., and Beaumelle, B. (1998) Involvement of ATP-dependent Pseudomonas exotoxin translocation from a late recycling compartment in lymphocyte intoxication procedure. Mol Biol Cell 9, 387-402.

(21) Lemichez, E., Bomsel, M., Devilliers, G., vanderSpek, J., Murphy, J. R., Lukianov, E. V., Olsnes, S., and Boquet, P. (1997) Membrane translocation of diphtheria toxin fragment A exploits early to late endosome trafficking machinery. Mol Microbiol 23, 445-457.

(22) Taupiac, M. P., Bebien, M., Alami, M., and Beaumelle, B. (1999) A deletion within the translocation domain of Pseudomonas exotoxin A enhances translocation efficiency and cytotoxicity concomitantly. Mol Microbiol 31, 1385-1393.

(23) Ostermeier, M., and Georgiou, G. (1994) The folding of bovine pancreatic trypsin inhibitor in the Escherichia coli periplasm. J. Biol. Chem 269, 21072-21077.

(24) Chaddock, J. A., and Roberts, L. M. (1993) Mutagenesis and kinetic analysis of the active site Glu 177 of ricin. Prot engineering 6, 425-431.

(25) Ogata, M., Chaudhary, V. K., Pastan, I., and FitzGerald, D. J. (1990) Processing of Pseudomonas Exotoxin by a cellular protease results in the generation of a 37,000-Da toxin fragment that is translocated to the cytosol. J Biol Chem 265, 20678-20685.

(26) Zhang, J. (1997) Use of biotinylated NAD to label and purify ADP-ribosylated proteins. Methods Enzymol 280, 255-265.

(27) Chung, D. W., and Collier, R. J. (1977) The mechanism of ADP-ribosylation of elongation factor 2 catalysed by fragment A from diphtheria toxin. Biochim. Biophys. Acta 483, 248-257.

(28) Twining, S. S. (1984) Fluorescein isothiocyanate-labeled casein assay for proteolytic enzymes. Anal Biochem 143, 30-34.

(29) Farenc, C., Fabreguette, J. R., and Bressolle, F. (2000) Pk-fit: a pharmacokinetic/pharmacodynamic and statistical data analysis software. Comput Biomed Res 33, 315-329.

(30) Fryling, C., Ogata, M., and FitzGerald, D. J. (1992) Characterization of a cellular protease that cleaves Pseudomonas Exotoxin. Infect immun 60, 497-502.

(31) van Deurs, B., Holm, P. K., and Sandvig, K. (1996) Inhibition of the vacuolar H(+)ATPase with bafilomycin reduces delivery of internalized molecules from mature multivesicular endosomes to lysosomes in HEp-2 cells. Eur J Cell Biol 69, 343-350.

(32) Umata, T., Moriyama, Y., Futai, M., and Mekada, E. (1990) The cytotoxic action of Diphtheria Toxin and its degradation in intact cells are inhibited by Bafilomycin A1, a specific inhibitor of vacuolar-type $\mathrm{H}^{+}$-ATPase. J Biol Chem 265, 21940-21945.

(33) Beaumelle, B., Bensammar, L., and Bienvenue, A. (1992) Selective translocation of the A chain of diphtheria toxin across the membrane of purified endosomes. $J$ Biol Chem 267, 11525-11531.

(34) Klingenberg, O., and Olsnes, S. (1996) Ability of methotrexate to inhibit translocation to the cytosol of dihydrofolate reductase fused to Diphtheria toxin. Biochem J 313, 647653.

(35) Vestweber, D., and Schatz, G. (1988) A chimeric mitochondrial precursor protein with internal disulfide bridges blocks import of authentic precursors into mitochondria and allows quantitation of import sites. J Cell Biol 107, 2037-2043. 
(36) Vincent, J. P., and Lazdunski, M. (1972) Trypsin-pancreatic trypsin inhibitor association. Dynamics of the interaction and role of disulfide bridges. Biochemistry 11, 2967-2977.

(37) Pastan, I., Chaudhary, V., and FitzGerald, D. (1992) Recombinant toxins as novel therapeutic agents. Ann. Rev. Biochem 61, 331-354.

(38) Gruenberg, J., and Maxfield, F. R. (1995) Membrane transport in the endocytic pathway. Curr Opin Cell Biol 7, 552-563.

(39) Ornatowski, W., Poschet, J. F., Perkett, E., Taylor-Cousar, J. L., and Deretic, V. (2007) Elevated furin levels in human cystic fibrosis cells result in hypersusceptibility to exotoxin A-induced cytotoxicity. J Clin Invest 117, 3489-3497.

(40) Makoid, M. C., Vuchetich, P. J., and Banakar, U. V. (1999) Basic Pharmacokinetics, The Virtual University Press.

(41) Chiron, M. F., Fryling, M. C., and FitzGerald, D. J. (1994) Cleavage of Pseudomonas Exotoxin and Diphtheria toxin by a furin-like enzyme prepared from beef liver. J Biol Chem 269, 18167-18176.

(42) Seetharam, S., Chaudhary, V. K., FitzGerald, D. J., and Pastan, I. (1991) Increased cytotoxic activity of Pseudomonas Exotoxin and two chimeric toxins ending in KDEL. J Biol Chem 266, 17376-17381.

(43) Smith, D. C., Spooner, R. A., Watson, P. D., Murray, J. L., Hodge, T. W., Amessou, M., Johannes, L., Lord, J. M., and Roberts, L. M. (2006) Internalized Pseudomonas exotoxin A can exploit multiple pathways to reach the endoplasmic reticulum. Traffic 7, 379-393.

(44) Carrel, T. P., Schwanda, M., Vogt, P. R., and Turina, M. I. (1998) Aprotinin in pediatric cardiac operations: a benefit in complex malformations and with high-dose regimen only. Ann Thorac Surg 66, 153-158.

(45) Himmelreich, G., Dooijewaard, G., Neuhaus, P., Kluft, C., Bechstein, W. O., and Riess, H. (1994) Increased urokinase-type plasminogen activator (u-PA) levels in graft liver perfusate and decreased single chain u-PA activation with higher levels of aprotinin. Thromb Haemost 71, 12-14. 


\section{TABLE 1}

Pharmacokinetics parameters of PE and BPTI-PE in mice. Mice were injected in the tail vein with $66 \mu \mathrm{g} / \mathrm{kg}$ of PE or BPTI-PE. Three groups of three mice were used for each toxin $(\mathrm{n}=9)$. Seric PE concentrations were monitored by ELISA over 120 min following injection. The log toxin concentration-time plot shows a biphasic response (Fig.9), indicating that the toxin distributes according to a two-compartment model (40). Data were analyzed using Pk-fit (29) and a two-compartment model to determine pharmacokinetics parameters of toxins. The significance of differences between data was assessed using an unpaired, two-sided Student's t-test $(* * *, \mathrm{p}<0.001 ; * *, \mathrm{p}<0.01)$. Results are mean $\pm \mathrm{SD}$.

\begin{tabular}{|l|c|c|}
\hline & PE & BPTI-PE \\
\hline $\mathrm{T}_{1 / 2}$ distribution (min) & $0.67 \pm 0.09$ & $0.77 \pm 0.04 * *$ \\
\hline Elimination half-time (min) & $18.0 \pm 0.5$ & $30.9 \pm 1.8 * * *$ \\
\hline Distribution volume (ml) & $2.3 \pm 0.1$ & $7.6 \pm 0.5 * * *$ \\
\hline Clearance (ml/min) & $2.4 \pm 0.1$ & $6.8 \pm 0.3 * * *$ \\
\hline
\end{tabular}




\section{Figure 1}

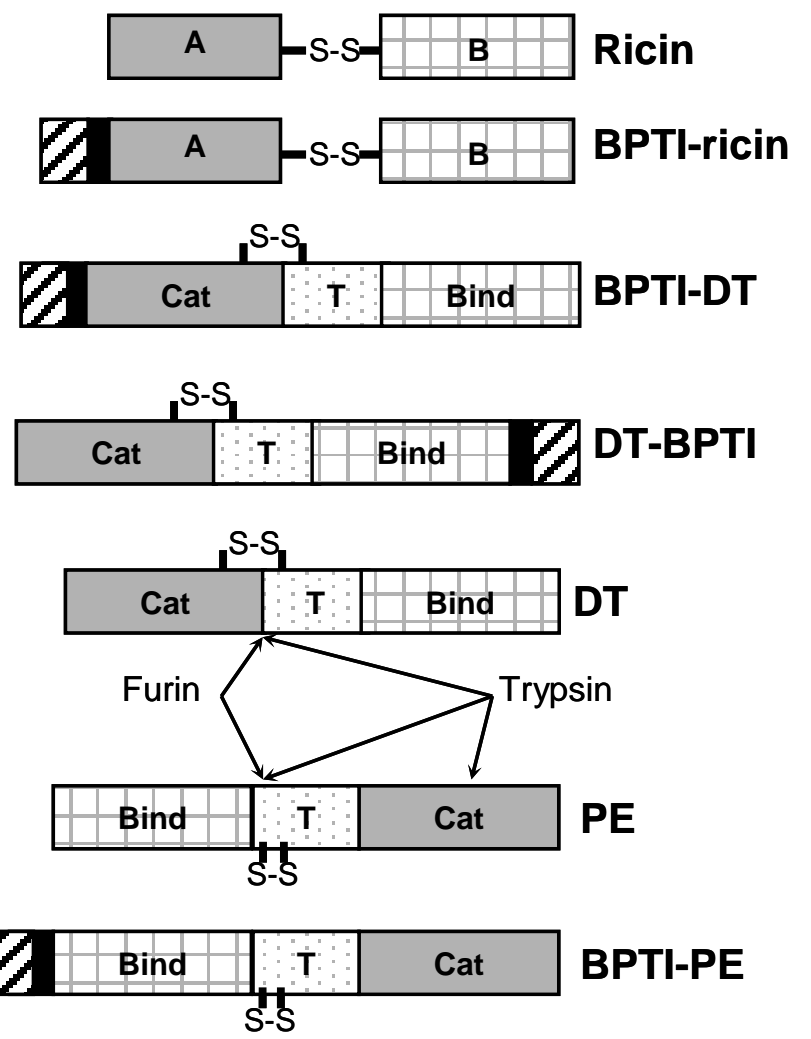

Figure 1. Schematic representation of the chimeras used for this study. A-chain (A) and Bchain (B) of ricin are represented, as well as PE and DT receptor-binding (Bind), translocation (T) and catalytic (Cat) domains. Implantations of BPTI (dashed box) and of the linker peptide (black box) are also indicated. Recombinant RTA (rRTA) and BPTI-RTA were expressed and purified from E. coli, before association with plant RTB to generate control ricin and BPTIricin, respectively. DT, BPTI-DT, DT-BPTI, PE and BPTI-PE were prepared from E. coli periplasm. Proteins were identified using Western blotting and were $>95 \%$ pure. Reported furin and trypsin cleavage sites within DT and PE are shown. Both enzymes cleave DT within the Arg-rich loop connecting the catalytic and translocation domains (9), and PE within a loop connecting the first two $\alpha$-helices of the translocation domain. This cut, followed by the reduction of the represented disulfide, generates a $37 \mathrm{kDa}$, carboxyl-terminal active fragment from PE. Trypsin can also inactivate PE by removing the last 123 residues from the catalytic domain (11). 
Figure 2A

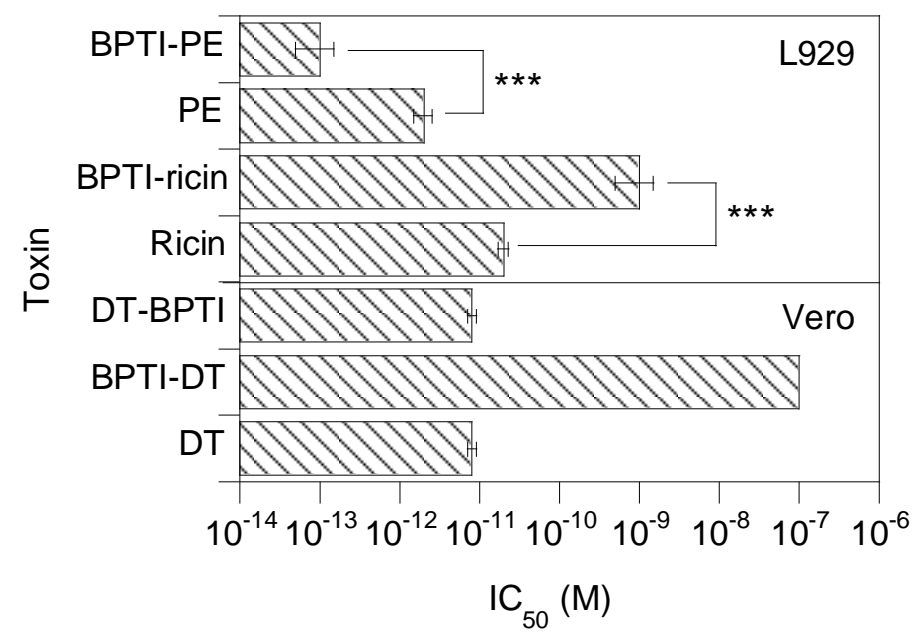

Figure 2B

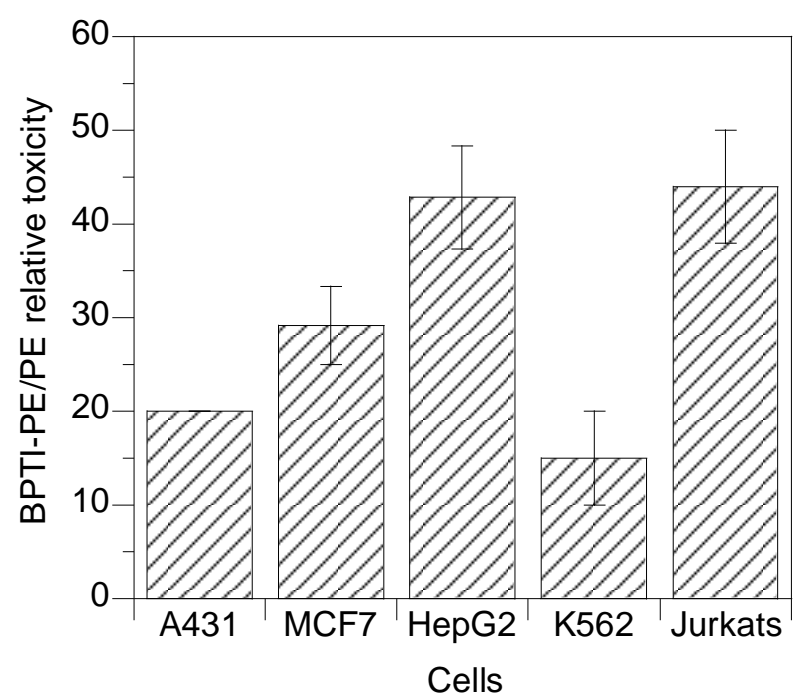

Figure 2C

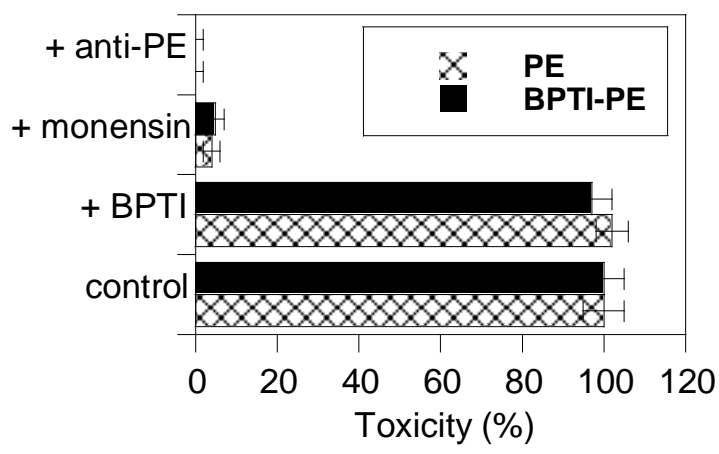


Figure 2. Cytoxicity of BPTI fusion proteins. (A) Vero and L929 cells are highly sensitive to DT and PE, respectively, and were used to determine the $\mathrm{IC}_{50}$ of these toxins. DT used in this study is a $\sim 500$-fold attenuated mutant (E148S) (21). BPTI-DT was essentially not toxic. Data are mean of three independent experiments performed in quadruplicate \pm S.E.M. The significance of differences between data was assessed using an unpaired, two-sided Student's t-test (***, p < 0.001). (B) BPTI-PE is more toxic than PE against human cancer cell lines. The relative toxicity, that represents the increase in toxicity due to BPTI fusion, is the $\mathrm{IC}_{50}$ (PE) / IC 50 (BPTI-PE) ratio for the indicated cell line. $\mathrm{IC}_{50}(\mathrm{PE})$ were $80 \mathrm{nM}(\mathrm{A} 431), 20 \mathrm{nM}$ (MCF7), 20 pM (HepG2), 30 nM (K562) and 2 nM (Jurkats). (C) Analysis of BPTI-PE toxicity. The $\mathrm{IC}_{50}$ of PE and BPTI-PE were measured on L929 cells in the absence or presence of $10 \mu \mathrm{M}$ BPTI, $10 \mathrm{nM}$ anti-PE or $100 \mathrm{nM}$ monensin, as indicated. Percentages of toxicity are $\mathrm{IC}_{50}($ control)//C 50 (treated) $(\%)$. 


\section{Figure 3}
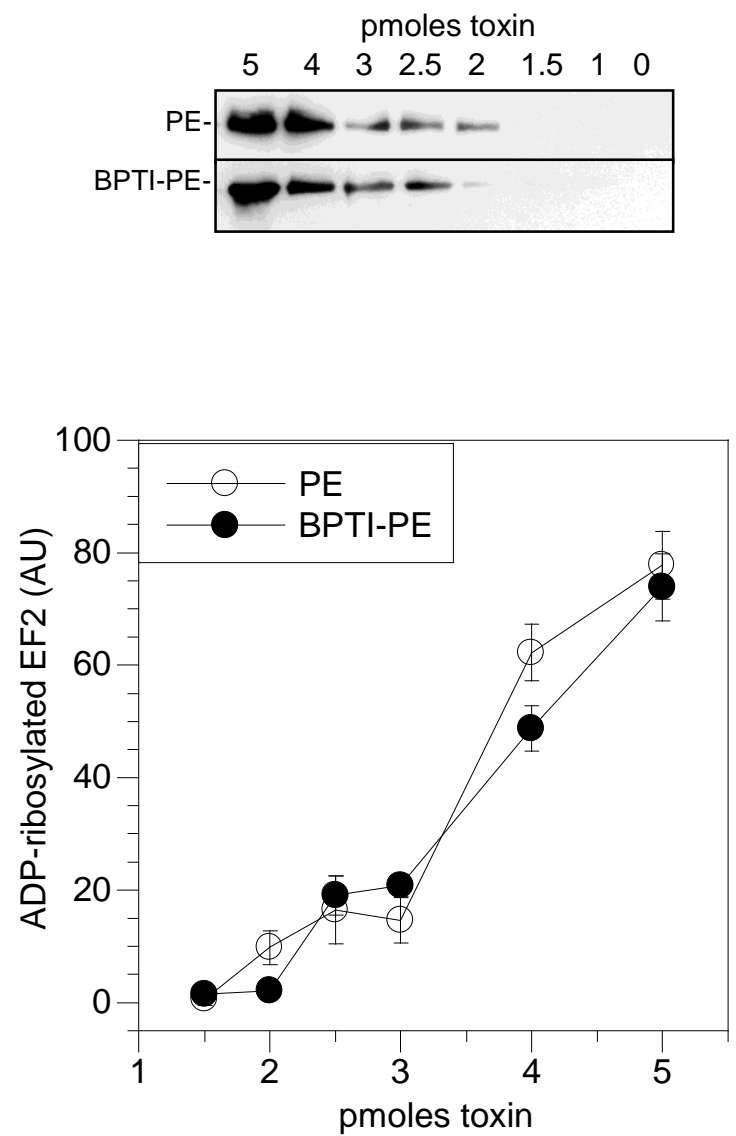

Figure 3. BPTI-PE retains the capacity to ADP-ribosylate EF2. The EF2-ADP-ribosylating activity of PE and BPTI-PE was tested using purified EF2 and 6-biotin-17-NAD. After 30 $\min$ at $25^{\circ} \mathrm{C}$, proteins were separated by SDS/PAGE before blotting and biotin detection using extravidin peroxidase and chimioluminescence. The bands from duplicate gels were quantified to prepare the plot. 
Figure 4A

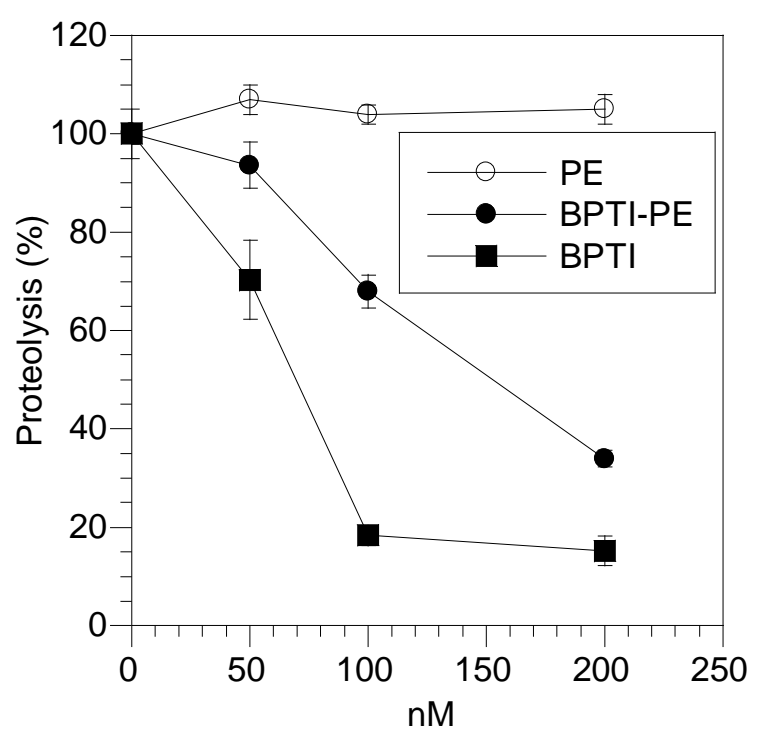

Figure 4B

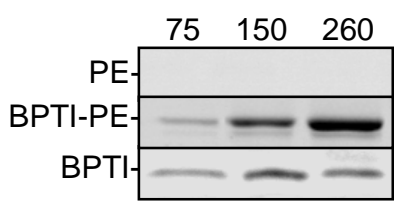

Figure 4. BPTI-PE displays antitrypsin properties. (A) Trypsin inbibitory activity in trans. Casein-fluorescein $(10 \mu \mathrm{g} / \mathrm{ml})$ was treated for $1 \mathrm{~h}$ at $25^{\circ} \mathrm{C}$ with $100 \mathrm{nM}$ trypsin in the presence of the indicated concentrations of PE, BPTI-PE or BPTI. Proteolysis was monitored using FRET efficiency. The amounts of PE and BPTI-PE required to inhibit proteolysis by $50 \%$ were $\sim 14$ and $\sim 31$ pmoles, respectively. BPTI-PE therefore retains $\sim 45 \%$ of BPTI antitrypsin activity. (B) BPTI-PE binds to trypsin. PE, BPTI or BPTI-PE (75, 150 or 260 pmoles) were mixed with trypsin-agarose ( 200 pmoles trypsin). After $15 \mathrm{~min}$ at room temperature, the gel was washed and bound-proteins were eluted using SDS/PAGE sample buffer. The polyacrylamide gels were stained with Sypro Ruby. A representative gel is shown. 


\section{Figure 5}

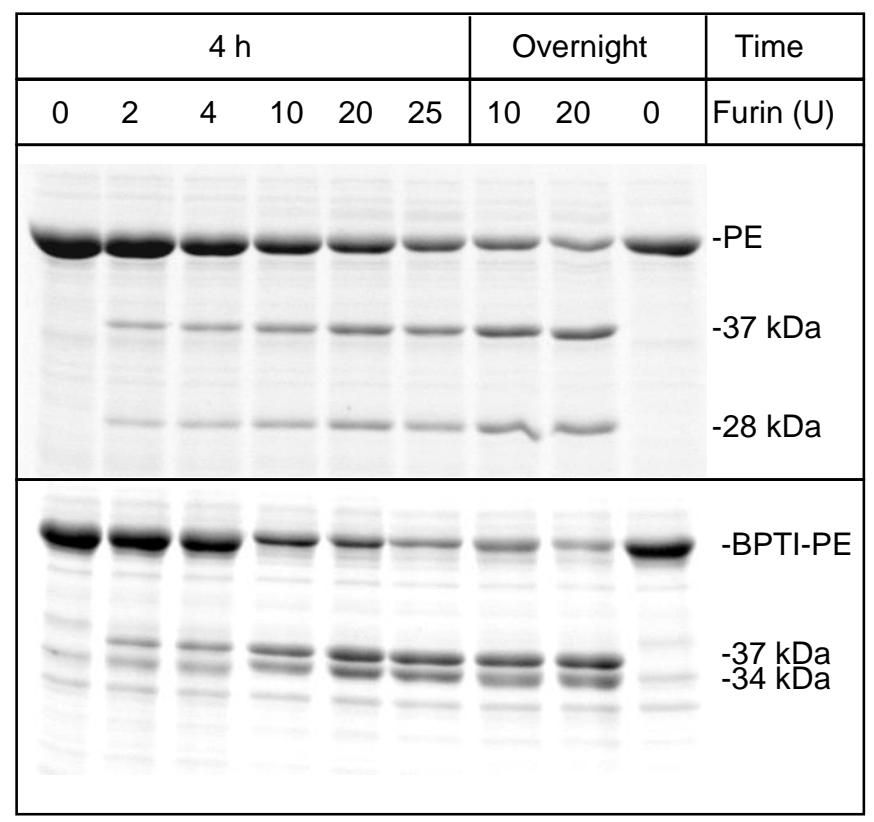

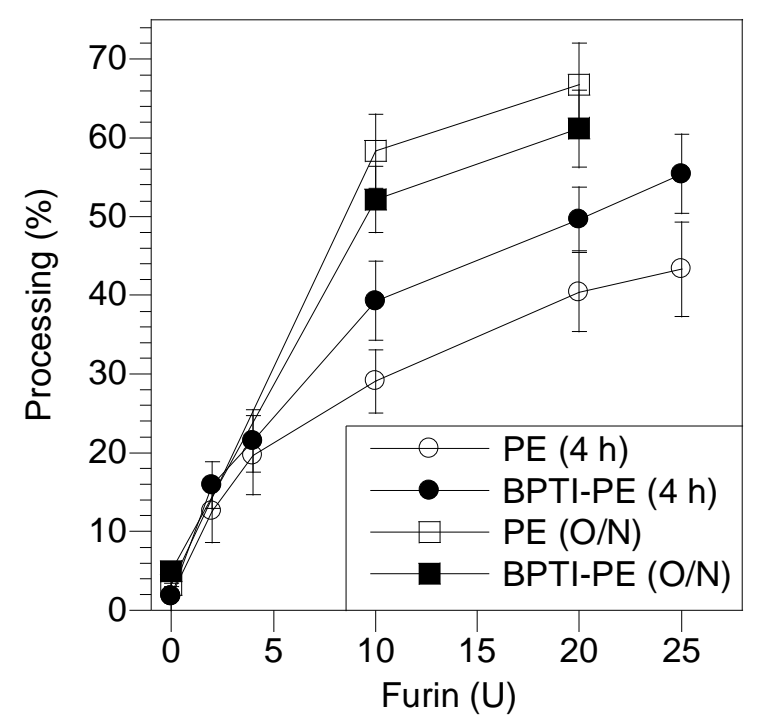

Figure 5. Processing of PE and BPTI-PE by purified furin. $6 \mu \mathrm{g}$ of PE or BPTI-PE were treated for $4 \mathrm{~h}$ or overnight $(\mathrm{O} / \mathrm{N})$ at $25^{\circ} \mathrm{C}$ with increasing concentrations of furin under acidic conditions ( $\mathrm{pH}$ 5.5, which is optimum for furin) before SDS-PAGE. The gels were stained with Sypro Ruby before band quantification. Furin processing generates the same carboxylterminal fragment of $37 \mathrm{kDa}$ for both PE and BPTI-PE. The presence of BPTI increases the size of the PE amino-terminal fragment from $28 \mathrm{kDa}$ to $\sim 34 \mathrm{kDa}$. Processing was calculated as $(37 \mathrm{kDa}+28$ or $34 \mathrm{kDa}) /($ entire toxin $+37 \mathrm{kDa}+28$ or $34 \mathrm{kDa})(\%)$. No significant difference of furin-mediated processing was observed between PE and BPTI-PE when using purified proteins. 


\section{Figure 6}
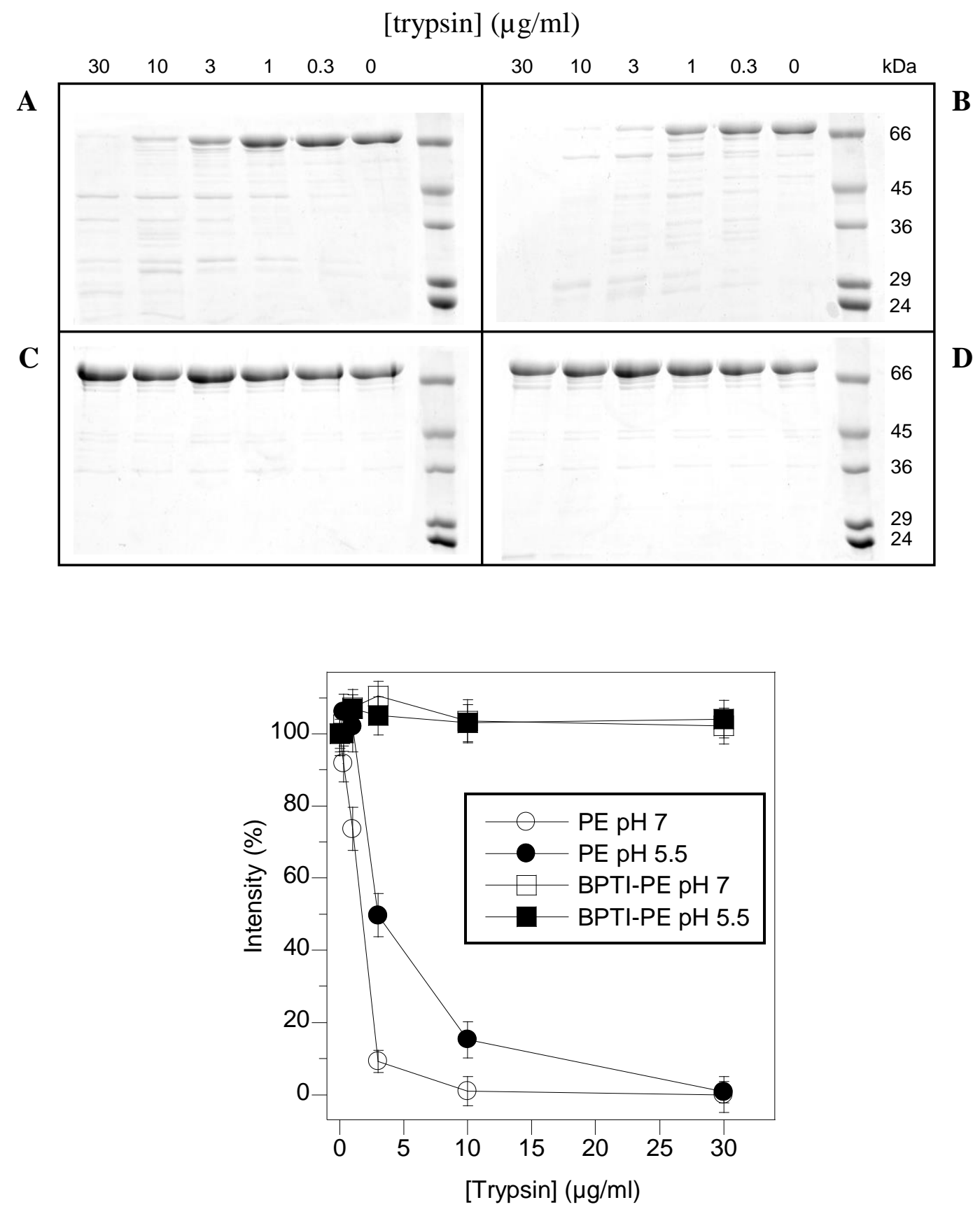

Figure 6. Susceptibility of PE and BPTI-PE to trypsin. $5 \mu \mathrm{g}$ of PE (A, B) or BPTI-PE (C,D) were treated for $30 \mathrm{~min}$ at $37^{\circ} \mathrm{C}$ with serial dilutions of trypsin under acidic $(\mathrm{pH} 5.5 ; \mathrm{A}, \mathrm{C})$ or neutral (pH 7.0; B, D) conditions before SDS-PAGE. The gels were stained with Coomassie blue. The bands from triplicate gels were quantified to generate the plot. The intensity of each band was normalized to the value obtained in the absence of trypsin. 
Figure 7A

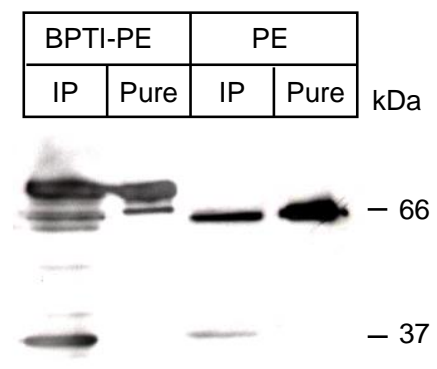

Figure 7B

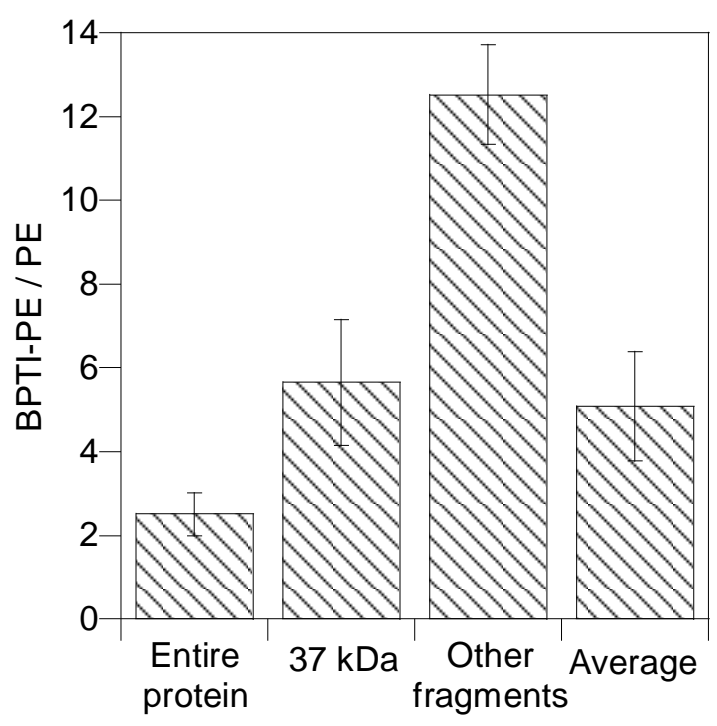

Figure 7. Intracellular stability of PE and BPTI-PE. L929 cells were incubated for $4 \mathrm{~h}$ at $37^{\circ} \mathrm{C}$ with $5 \mathrm{nM}$ PE or BPTI-PE before washing and chasing for $30 \mathrm{~min}$. Cells were lysed for PE immunoprecipitation before SDS-PAGE, transfer and anti-PE Western blot. (A) Immunoblot; IP, toxin immunoprecipitated from treated cells and Pure, purified toxins. (B) Quantification of the main immunoprecipitated toxin fragments. Films from three independent experiments were scanned and bands corresponding to the entire toxin, active $37 \mathrm{kDa}$ fragment and other fragments were quantified for both PE and BPTI-PE. The intensity ratio (BPTI-PE/PE) was calculated for each band to normalize data that are mean \pm SEM. The $28 \mathrm{kDa}$ fragment of PE is poorly immunoprecipitated and is not visible on these films. 


\section{Figure 8A}

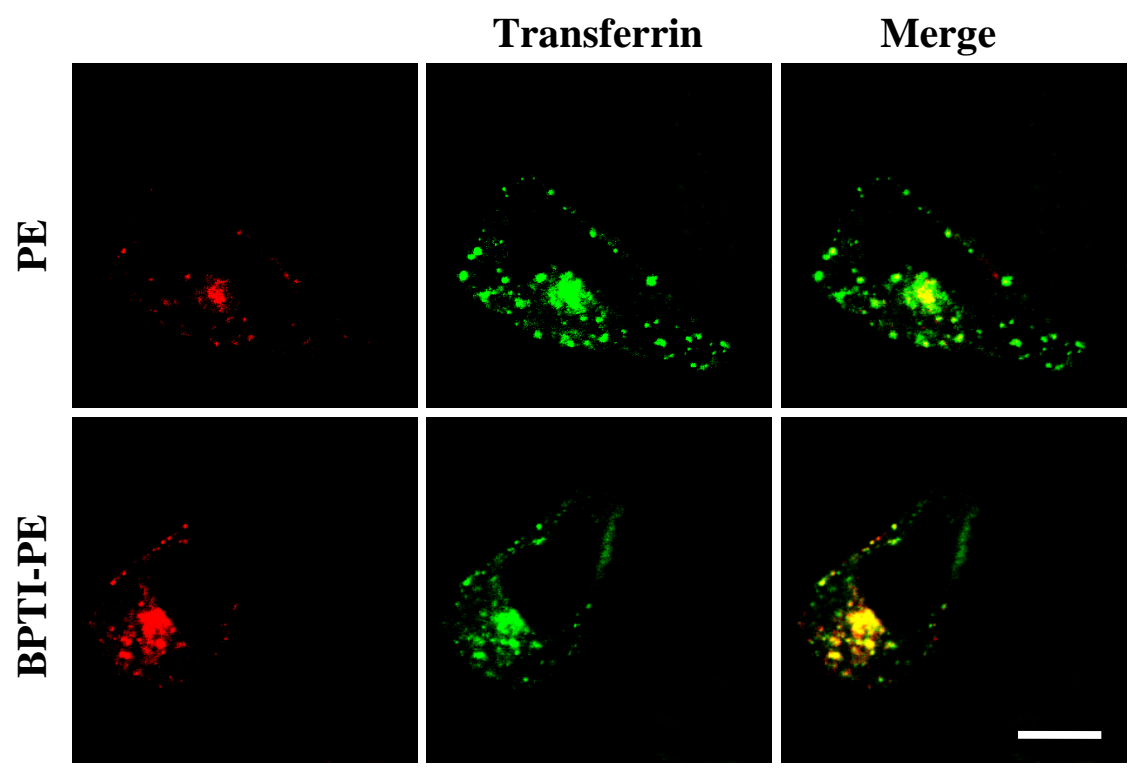

Figure 8B

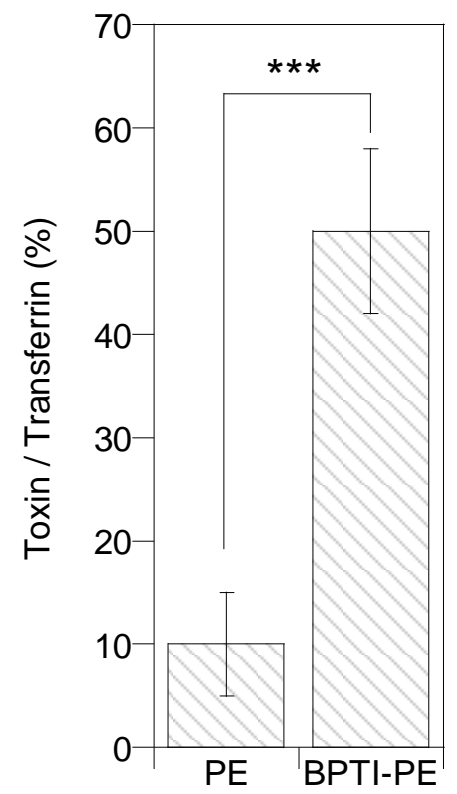

Figure 8. Endosomal stability of PE and BPTI-PE. (A) Representative confocal images. L929 cells were labeled for $45 \mathrm{~min}$ at $37^{\circ} \mathrm{C}$ with $100 \mathrm{nM}$ transferrin-FITC and $15 \mathrm{nM}$ of PE or BPTI-PE, then processed for immunofluorescence detection of PE before confocal microscopic examination. Microscope settings were identical for PE and BPTI-PE and a representative median optical section is shown (bar, $10 \mu \mathrm{m}$ ). (B) Quantification of internalized toxins. Transferrin signal intensity was used to normalize the data ( $\mathrm{n}>30$ cells). The significance of differences between PE/ Transferrin and BPTI-PE/ Transferrin ratios was assessed using an unpaired, two-sided Student's t-test (***, p < 0.001). 
Figure 9

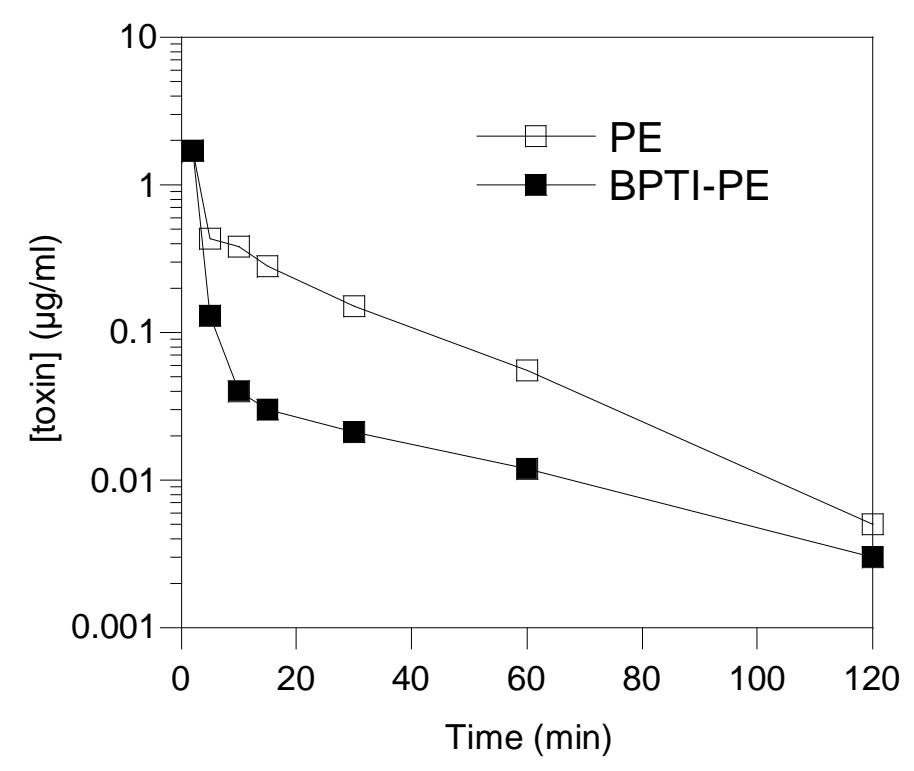

Figure 9._Stability of PE and BPTI-PE in mice. Mice were injected in the tail vein with 66 $\mu \mathrm{g} / \mathrm{kg}$ of PE (open symbols) or BPTI-PE (closed symbol). Blood samples were collected after the indicated period of time and PE concentrations were assayed by ELISA. The indicated serum levels are the means of three groups of three mice. Error bars are within the symbol size. These data were used to calculate the pharmacokinetics parameters presented in Table 1. 
Méré et al. Supplemental Fig.1. Protein sequence of BPTI-PE.

MKKTAIA IAVALAGFATVAQAAP KDNP QGRP DFCLEPPYTGPCKARI IRYFYNAKAGLCQTFVYGGCRAKRNNFKSAEDCMRTCGGAASASTPE PDPEKLAEEAFDLWNECAKACVLDLKDGVRSSRMSVDPAIADTNGQG VLHYSMVLEGGNDALKLA IDNALS I TSDGLT IRLEGGVEP NKPVRYS YTRQARGSWS LNWLVP I GHEKP SN IKVF I HELNA GNQLSHMSP IYT I EMGDELLAKLARDATFFVRAHE SNEMQP TLA I SHAGVSVVMAQTQPR REKRWSEWAS GKVLCLLDP LDGVYNYLAQQRCNLDDTWEGKIYRVLA GNPAKHDLDIKP TVISHRLHFP EGGSLAALTAHQACHLPLETFTRHR QPRGWEQLEQCGYPVQRLVALYLAARLSWNQVDQVIRNALASP GSGG DLGEAIREQP EQARLALTLAAAESERFVRQGTGNDEAGAANADVVSL TCPVAAGECAGPADSGDALLERNYP TGAEF LGDGGDVSF S TRGTQNW TVERLLQAHRQLEERGYVFVGYHGTFLEAAQS IVFGGVRARSQDLDA IWRGFY IAGDPALAYGYAQDQEPDARGR IRNGALLRVYVPRSSLP GF YRTS LTLAAP EAAGEVERL I GHP LP LRLDA I TGP EEEGGRLET ILGW P LAERTVVIP SA IP TDPRNVGGDLDP SS IPDKEQAISALPDYASQPG KPPREDLK

Signal

From mature OmpA

BPTI

Spacer

Mature $\mathrm{PE}$ 